\title{
Demand Side Management in a Restructured Multi-Agent System-Based Environment
}

\author{
Yousef Abdollahi ${ }^{1}$, Alireza Sedaghati ${ }^{2}$ \\ ${ }^{1}$ Shahab-Danesh Institute of Higher Education, Qom, Iran, MS. Student in EE \\ ${ }^{2}$ Shahab-Danesh Institute of Higher Education, Qom, Iran, $\mathrm{PhD}$ in $\mathrm{EE}$
}

\begin{abstract}
An optimization-based model is presented in this paper to conduct load shifting strategy in frame of the concept of smart grid. In this model, those factors of load management, production and store are defined. One of important features if this plan is the point that electric vehicles with capacity of V2G are considered in it. This capacity makes it possible for electric vehicles to inject power into the grid. This property can be used for load shifting, congestion management and load profiles flattening. The proposed method is tested for a sample system. The studied grid is Standard 37-Bus IEEE Grid that is a distribution grid. The function and ability of proposed method and effect of hourly prices of electricity on load curve flattening is well demonstrated in this grid.
\end{abstract}

Keywords: Demand Side Management, electric vehicles, smart grid, V2G capability

\section{INTRODUCTION}

Moving toward smart grid (SG) depends on using new technologies and tools in existing electricity grids. Among unique characteristics of smart grids, distributed generation is a common characteristic in smart grids. In addition, the nature of these generators is variable and can be renewable such as wind turbines, solar panels, water and heat cogeneration, fuel cells, micro turbines or diesel generators. Equipment that can store energy such as electric batteries are able to contribute to smooth stochastic behavior of renewable units. This would make it simple to connect these units to grid. The future generation of electricity grids would make it possible for users to use this energy in transportation system [1]. Smart grids include various units that can be communicating with each other. This mutual relation makes it possible to create an economical relation to receive and deliver electric energy. On the other hand, it would be possible to eliminate occurred technical problems.

These units in a smart grid can response to changes in sale and purchase prices of electricity of the main electricity grid with the aim of minimizing the costs of their required energy. Another aim can be maximizing the earnings obtained from selling energy to grid. The basic aspect of numerous capabilities provided by smart grids is that electrical power engineering technologies can be integrated with Information Technology and Telecommunication. Therefore, this integration would make it possible to improve reliability, efficiency and network utilization capabilities [2].

Among interesting features if smart grid, the concept of demand side management (DMS) has drawn attention of many researchers and load response among DSM strategies have been extensively considered [3-5]. Load response can be defined as the changed common load in its common consumption pattern in response to price signals [6]. In addition to gaining economic profit from this program, these kinds of projects can be applied to prevent from load peak may happen in some daily hours. This application would improve return and reliability of grid [7-10]. It is expected that some advantages such as improved system yield, power supply security, reduced required forces for generators and eliminated environmental hazards are obtained when using DSM. Of course, there are different challenges in this method that should be eliminated while its proper infrastructure is not prepared at first [11]. Moreover, other energy generation resources that can be used in smart grid should be considered when using DSM [12-13]. In this regard, some smart grid defined projects are completing and progressing all around the world [14-15].

The energy planning issue for a predicted load with the aim of minimizing the total cost has been studied in different presented articles in this field [6-32]. Regardless of proposed articles in field if 
energy planning, various articles have studied energy planning issue in grids equipped with electric vehicles (EV) [33-40]. The issue related to EVs [41-45] and their environmental implications [46-48] have been studied in some of these papers. In a paper, EVs values have been analyzed as the electricity grid resources and the battery charging plan of EVs has been modeled [49]. This issue is a unit commitment (UC) planning model of power system that is formulated as a Mixed Integer Linear Program (MILP). The purpose of this model is to minimize the total cost of system including traditional generators' costs and EVs exploitation costs. This study has considered economic and environmental effects on a grid regardless of distributed energy sources (DER) and virtual power plants (VPP). This model has been used in paper [50] considering another model to charge and move vehicles. Combining these two models, this paper has evaluated incentives for drivers with different tariffs. However, the capability of EV batteries is not used as reservoir at this study. The energy planning issue in VPP is presented in [51] considering technical constraints such as size, angle and voltage of buses. At this study, authors have conducted charge and discharge of EVs through integrating them in a 10-nodes unit. The objective function of the introduced model is defined as cost minimizing but the price of EVs' charge is added to objective function with a negative coefficient. Therefore, this model in fact minimizes the cost minus earning. In such manner, objective function would lead to a programming for EVs that these vehicles are charged at the time intervals with higher costs. The size of presented objective function by this study is always positive because the obtained earning from time inelastic (TIE) loads is not considered in objective function.

Electric vehicles in a power system can be considered as opportunities or threats for system. In other words, if these vehicles are inconsistently charges they may cause overload in grid particularly at the time of returning home that is along with pick time of grid [52]. Since the accessibility time to these vehicles for charge is more than required time for their discharge, the charging time can be transferred to non-peak times to avoid applying this overload to power network. In reference [53], effects of electric vehicles on power grid is analyzed using RECAPS software proposing a solution to timing electric vehicles' charging with the aim of filling gaps of daily load curve that is providing different prices for electricity in different daily hours in order to encourage owners to charge their vehicles at low-load hours. Reference [54] has provided a method entitled shifted rapid time charging in specific hours to avoid charging within peak load intervals that was seen for heavy loads before.

To simplify the implementation of proposed method in real systems, mots of measurements in smart grid will be done by agents. To conduct such measurements, agents would cat based on their considered objective. In some cases, they use information prepared by SG operator. Some made decisions by agents can be a little changed by grid operator (central corrector) to correct the violated constraints of smart grid utilization.

A multiple agents-based model has been proposed in this article for demand side management. In this model, power grid is divided into several smaller parts and each part is controlled by an agent. The task of each agent is to maximize its profit. Therefore, each agent can maximize its profit in accordance with the sell and purchase price of electricity as well as situation of generating units. The assumption of this model is that a part of consuming load by users is transferable and the client can transfer a part of load to other hours. On the other hand, electric vehicles are considered in this model as one of bases of smart grid. Wind, solar, and battery units are some of energy generating resources considered in this paper. Every agent would send its net consuming/generating power to grid operator and this operator considers generating/consuming capability of all agents as well as consuming load by clients performing relevant calculations to examine whether the utilization constraints of grid are violated or not considering the announced conditions. If the constraints are violated, new settings are announced within an optimal load distribution with the aim of minimizing changes of announced settings by agents and eliminating violated constraints.

The following sections of paper are as follows: second section includes the proposed plan and method with relevant equations. Third section includes the obtained results of simulation. Finally, the fourth section includes the obtained conclusions from simulation.

\section{PRoposed Model}

The proposed model of this paper is based on smart agents. The considered agents consist of a part of system and include some buses, loads, generation resources and batteries.

International Journal of Research Studies in Electrical and Electronics Engineering (IJRSEEE) Page | 2 
Focus of this method is on created load shifting by agents in SG. This load shifting is done to maximize the profit or minimize the cost. Number of periods that loads can be shifted (either upward or downward) is modeled using variable $\mathrm{k}$ that is an important variable.

Agents can purchase the energy from grid or sell it and it is feasible if it is technically practical. Every agent would make relevant decisions to itself personally and separately without any central decisionmaking unit. The main electricity grid as slag node is considered with infinite capacity.

The proposed model for SG exploitation includes two steps. At the first step, a market-based response is calculated and feasibility of this program is technically evaluated at the second step. SG exploitation beside these steps can be used as exploitation algorithm.

In this relation, the agents should consider uncertainty of renewable units. This uncertainty can be modeled using scenarios tree. On the other hand, the information of required load in day is predicted in accordance with information of previous days in relation with load level of each agent.

Agents make their decisions based on an optimization model. This model is a Mixed Integer Linear Program that can be only a Linear Program in some cases.

\subsection{Modeling Network Loads}

The loads are capable of transferring a part of their load to other hours in proposed model. This load shifting is related to electricity spot prices. Therefore, the predicted initial load of $\Theta_{n . t}$ is defined as total constant load $\phi_{n, t}$ and shifting load $\gamma_{n, t}$ that is a part of total load of model. This load for each time and node is defined as follows:

$\Theta_{n . t}=\phi_{n, t}+\gamma_{n, t}=\phi_{n, t}+f_{e}+\Theta_{n, t}$

When each agent makes its decisions based of the obtained results of optimization issue them total load is changed to $\Phi_{n . t}^{e}$ and the shifted load will be optimized as ${ }_{n, t}^{e}$. Figure 1 illustrates load constraints in load shifting mechanism. The most time interval in which, loads can shift upward or downward is indicated with parameter $\mathrm{k}$. it is assumed here that a part of loads can be shifted.

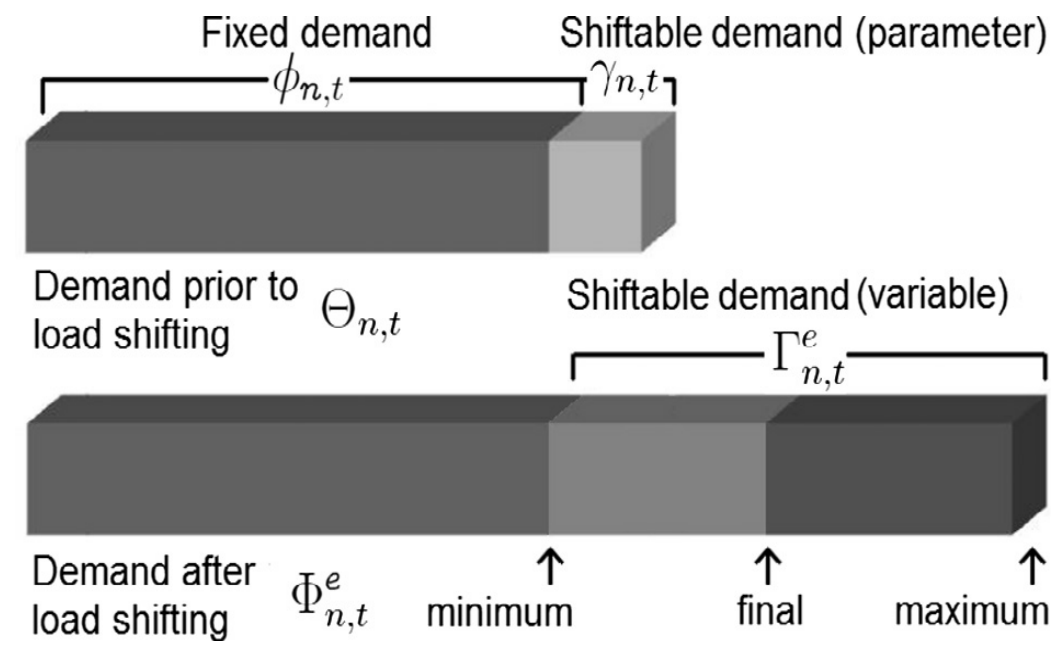

Figure1. Relevant parameters and variables to load

\subsection{Modeling Generating Units}

Two types of generators are considered in this paper that include renewable and nonrenewable. Renewable generator $\mathrm{j}$ is determined by its relevant exploitation cost. This generator has four types of costs including variable cost ${ }^{\mu_{j}}$, fixed cost $\iota_{j}$. , turning on cost ${ }^{\zeta_{j}}$, and turning off cost ${ }^{\zeta_{j}}$. Exploitation from this generator is related to the price of hourly price and cost of this unit. Technical constraints of these units include minimum and maximum productive capability of them that are indicated by $P_{g . j}^{\min }$ and $P_{g . j}^{\max }$ respectively. The generated power by renewable units that are solar and wind units here is modeled as a set of scenarios. The determine value of each of these units is calculated using same 
technical features, wind speed and radiation. The obtained values are combined with each other to consider the possible moods at the time of exploitation.

\subsection{Reserviors}

Two types of fixed and removable reservoirs are considered in proposed model. The fixed storage equipment are considered as a set of batteries and fixed batteries are modeled so that battery can be charged and discharged with respectively functional return of $\eta_{C}, \eta_{D}$. The considered limitations for capability for charging/discharging that are indicated by $P_{b}^{c, \text { max }}, P_{b}^{d, \text { max }}$. Existing energy in battery is modeled using state of charge (SOC) parameter.

Finally, mobile reservoir equipment is considered as electric vehicles. As it was said about fixed batteries, this type of equipment is along with constraint. However, some other options should be considered for these types of batteries in this case.

\section{OPTIMIZATION ISSUE}

This section includes mathematical relations between parameters and variables related to elements of each agent that are indicated as an optimization issue. This issue is a type of MIPL. Objective function of agents is maximizing the expected profit defined in equation 2.

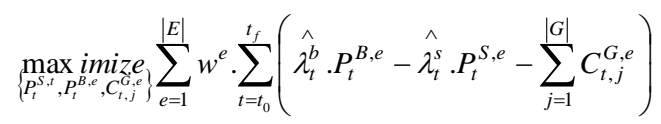

Where, $\hat{\lambda}_{t}^{b}$ and $\hat{\lambda}_{t}^{s}$ are [predicted price for buying and selling energy of electricity market (parameter) in time of $\mathrm{t}, P_{t}^{B, e}$ and $P_{t}^{S, e}$ the bought power and sold power (variable), $C_{t, j}^{G, e}$ is the cost function of power generation for nonrenewable generator of $\mathrm{I}, \mathrm{T}_{0}$ the starting time of study period, and $\mathrm{T}_{\mathrm{f}}$ is the final time of study period.

\subsection{Power Balance Constraint}

Equality between productive and purchased capabilities with consuming capability is considered in this constraint as follows:

$$
\begin{aligned}
& P_{t}^{S, e}-P_{t}^{B, e}=\sum_{i=1}^{|R|} P_{i, t}^{R, e}+\sum_{j=1}^{|G|} P_{j, t}^{G, e}+ \\
& \sum_{b=1}^{|B|}\left(P_{b, t}^{d, e}-P_{b, t}^{c, e}\right)-\sum_{n=1}^{|A|} \Phi_{n, t}^{e} \quad \forall t, \forall e . \\
& 0 \leq P_{t}^{B, e} \leq \beta_{t}^{e} \cdot X \quad \forall t, \forall e \\
& 0 \leq P_{t}^{S, e} \leq\left(1-\beta_{t}^{e}\right) \cdot X ; \quad \forall t, \forall e
\end{aligned}
$$

Where, ${ }_{i, t}^{R, e}$ is productive capability of generator $\mathrm{i}$ at $\mathrm{t}$ time in scenario e, ${ }^{P_{j, t}^{G, e}}$ is productive capability of generator $\mathrm{j}$ at $\mathrm{t}$ time in scenario e, ${ }_{b, t}^{d, e}$ is productive capability of battery $\mathrm{b}$ at $\mathrm{t}$ time in scenario e, $P_{b, t}^{c, e}$ is consuming capability of battery $\mathrm{b}$ at $\mathrm{t}$ time in scenario e, $\Phi_{n, t}^{e}$ is total load in node $\mathrm{n}$ at $\mathrm{t}$ time and scenario $\mathrm{e}, \beta_{t}^{e}$ is binary variable, $\mathrm{X}$ is a enough large parameter that can be set to limit agent capacity for power transferring. This limitation might be related to transfer line of agent or other issues. It should be mentioned that relevant term to vehicles is similar to terms related to batteries.

\subsection{Load Shifting Constraints}

$$
\begin{array}{ll}
\Phi_{n . t}^{e}=\phi_{n, t}+\Gamma_{n, t}^{e} \quad \forall_{t}, \forall_{n}, \forall_{e} & \\
\Phi_{n, t}^{e}=\Theta_{n, t}+\sum_{t^{\prime}} M_{n, t^{\prime}, t}^{e}-\sum_{t^{\prime}} M_{n, t, t^{\prime}}^{e} & \forall_{t}, \forall_{n}, \forall_{e} \\
\Gamma_{n . t}^{e}=\gamma_{n, t}+\sum_{t^{\prime}} M_{n, t^{\prime}, t}^{e}-\sum_{t^{\prime}} M_{n, t, t^{\prime}}^{e} & \forall_{t}, \forall_{n}, \forall_{e} \\
\Gamma_{n . t}^{e}=\gamma_{n, t}+\sum_{t^{\prime}} M_{n, t^{\prime}, t}^{e}-\sum_{t^{\prime}} M_{n, t, t^{\prime}}^{e} & \forall_{t}, \forall_{n}, \forall_{e}
\end{array}
$$




$$
\begin{aligned}
& \sum_{t^{\prime}} M_{n, t, t^{\prime}}^{e} \leq \gamma_{n, t} \quad \forall_{t}, \forall_{n}, \forall_{e} \\
& M_{n, t, t^{\prime}}^{e}=0 \text { if }\left\{\begin{array}{l}
t=t^{\prime}, \\
t+k \leq t^{\prime} \quad \text { or } t^{\prime}+k \leq t \quad \forall n, \forall e
\end{array}\right. \\
& 0 \leq \Gamma_{n, t}^{e} \leq K_{\varepsilon} \cdot \phi_{n, t} \quad \forall_{t}, \forall_{n}, \forall_{e}
\end{aligned}
$$

Where, $\Phi_{n . t e}^{e}$ is the optimal load indicating real load consumed at t time defined as the sum of fixed $\operatorname{load} \phi_{n, t}$ and shifted load ${ }_{n, t}^{e} . \phi_{n, t}$ is the fixed load of node $\mathrm{n}$ at $\mathrm{t}$ time, ${ }_{n, t}^{e}$ is the optimal shifted load of node $\mathrm{n}$ at $\mathrm{t}$ time. Total load of node $\mathrm{n}$ at $\mathrm{t}$ time is indicated in equation 7 that is defined as sum of transferred energy from time period of $\mathrm{t}$ to time period of $\mathrm{t} M_{n, t^{\prime}, t}^{e}$ minus transferred energy from $\mathrm{t}$ time to another time period $\mathrm{t}$ in ${ }_{n, t^{\prime}, t}^{e}$. This term is considered for each node and scenario.

\subsection{Cost and Constraints of Nonrenewable Generators}

$$
\begin{aligned}
& C_{t, j}^{G, e}=\mu_{j} \cdot P_{t . j}^{G, e}+t_{j} \cdot v_{t, j}^{G, e}+ \\
& \zeta_{j} \cdot y_{t . j}^{G, e}+\varsigma_{j} \cdot s_{t . j}^{G, e} \quad \forall t, \forall j, \forall e \\
& v_{t . j}^{G, e} \cdot P_{g . j}^{\min } \leq P_{t . j}^{G, e} \leq v_{t . j}^{G, e} P_{g . j}^{\max } \quad \forall t, \forall j, \forall e \\
& y_{t . j}^{G, e}-s_{t . j}^{G . e}=v_{t . j}^{G, e}-v_{t-1 . j}^{G, e} \quad \forall t, \forall j, \forall e
\end{aligned}
$$

Where, ${ }_{t . j}^{G, e}$ is binary variable that is equal to 1 if the generator $\mathrm{j}$ is in orbit at time; otherwise, it will be equal to zero. ${ }^{y_{t . j}^{G, e}}$ is the binary variable and will be equal to 1 if generator $\mathrm{j}$ is turned up at time; otherwise, it will be equal to zero. $s_{t . j}^{G . e}$ is binary variable that will be equal to 1 if generator $\mathrm{j}$ is turned off at $\mathrm{t}$ time; otherwise, it will be equal to zero.

\subsection{Fixed Batteries Constraints}

$$
\begin{aligned}
& 0 \leq P_{b, t}^{d, e} \leq y_{b, t}^{d, e} \cdot P_{b}^{d, \max } \quad \forall t, \forall b, \forall e \\
& 0 \leq P_{b, t}^{c, e} \leq\left(1-y_{b, t}^{d, e}\right) P_{b}^{c, \text { max }} \quad \forall t, \forall b, \forall e \\
& 0 \leq S_{b, t}^{e} \leq S_{b}^{\max } \quad \forall t, \forall b, \forall e \\
& S_{b, t}^{e}-S_{b, t-1}^{e}=\eta_{C} \cdot P_{b, t}^{c, e}-\left(\frac{1}{\eta_{D}}\right) P_{b, t}^{d, e} \quad \forall t, \forall b, \forall e \\
& S_{b, t_{0}}^{e}=S_{b, t_{f}}^{e} \quad \forall b, \forall e
\end{aligned}
$$

Where, ${ }_{b, t}^{e}$ indicates SOC value of vehicle. Equation 20 guarantees that initial and final values of $\operatorname{SOCs}\left(S_{b, t_{0}}^{e}, S_{b, t_{f}}^{e}\right)$ are equal in order to obtain unreal responses.

\subsection{Modeling Electric Vehicles}

$$
\begin{aligned}
& y_{v, t}^{d, e} \cdot P_{v}^{\min } \leq P_{v, t}^{d, e} \leq y_{v, t}^{d, e} \cdot P_{v}^{\max } \quad \forall t, \forall b, \forall e \\
& y_{v, t}^{c, e} \cdot P_{v}^{\min } \leq P_{v, t}^{c, e} \leq y_{v, t}^{c, e} \cdot P_{v}^{\max } \quad \forall t, \forall v, \forall e \\
& y_{v, t}^{c, e}+y_{v, t}^{d, e} \leq 1 \quad \forall t, \forall v, \forall e \\
& S_{v, t_{e}}^{e}=S_{v}^{\max } \quad \forall v, \forall e \\
& S_{v, t_{m+1}}^{e}=S_{v, t_{m}}^{d, e}-K_{c}^{t_{m} . \vartheta \quad} \quad t_{m} \in T_{M}, \forall v, \forall e
\end{aligned}
$$

Where, ${ }^{y_{v, t}^{c, e} e}$ is binary variable expressing whether vehicle $\mathrm{v}$ is charging at $\mathrm{t}$ time or not. ${ }^{y_{v, t}^{d, e}}$ is binary variable expressing whether vehicle $\mathrm{v}$ is discharging at $\mathrm{t}$ time or not. Equation 24 indicates that SOC of vehicle should be maximized at $t_{e}$ time. Variable of vehicle SOC should be minimized in accordance with equation 25 when vehicle is moving during $t_{m}$ time. 


\section{Simulation Results}

This part of study includes simulation results. The studied grid is 37-Bus IEEE Grid that its one-linear diagram is illustrated in figure 2. All relevant information to this grid is adopted from [55]. As shown in figure 2, 7 agents are considered that the range of each of them is determined. Productive capability of wind and solar units in different scenarios, grid load in different daily hours as well as buying and selling prices of energy are illustrated in figures 3-6 respectively.

According to the mentioned points in modeling section, considering that each wind and solar unit has 4 scenarios, the total scenarios will be equal to 16 . We will have 384 profiles in total considering 16 scenarios and 24 hours per day while their demonstration in one figure is not useful. Hence, grid voltage profile within different hours per day for first scenario is illustrated in figure 7 as the sample. Figure 8 depicts grid load profile within different scenarios.

As it is seen, load changing pattern is the same in all of scenarios with a minor change in some daily hours. Therefore, it can be concluded that a minor change in productive capability of renewable units has not a considerable effect on grid load change trend. As it is shown, grid load is considerable increased during 4-6 hours compared to base state and it is decrease in load peak hours.

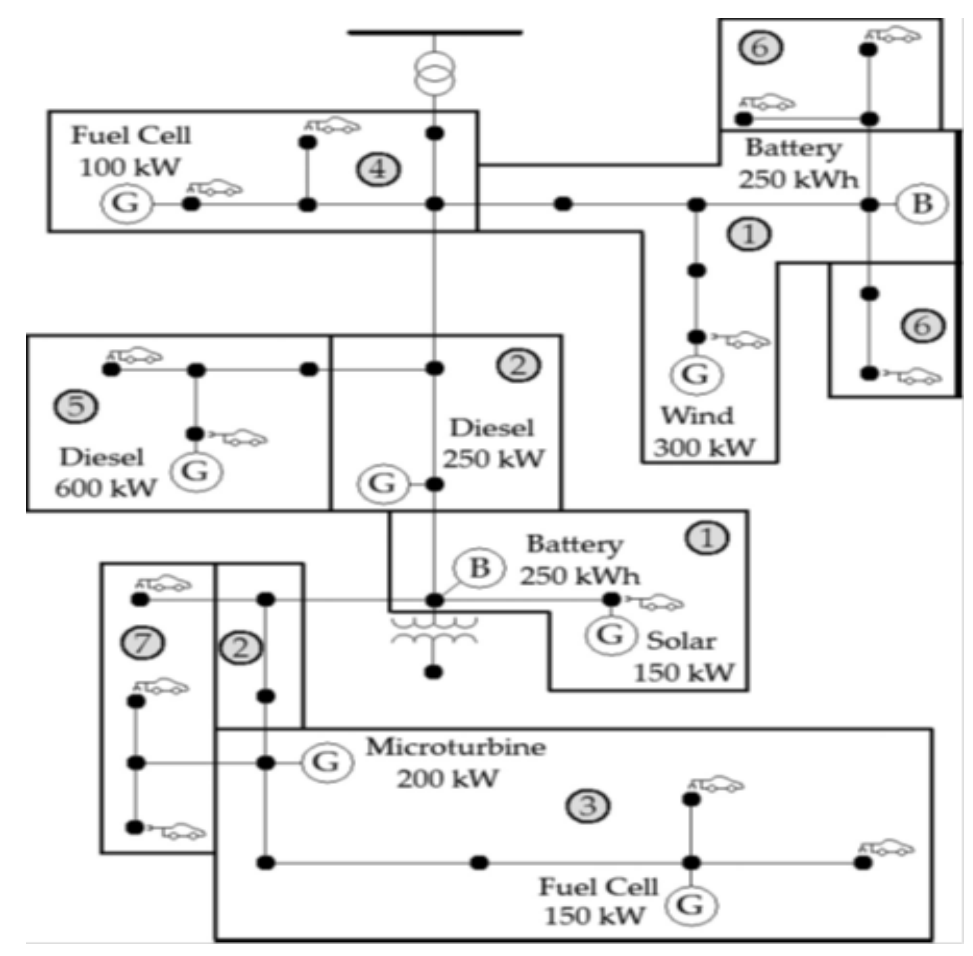

Figure2. One-linear diagram of 37-bus IEEE grid

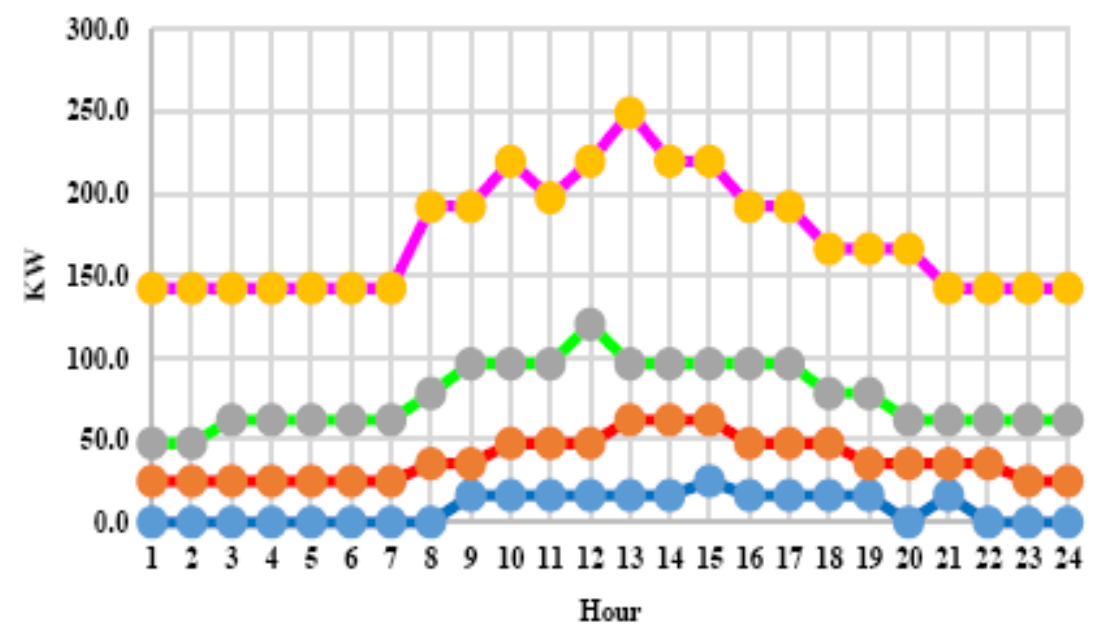

Figure3. Productive capability of wind unit for different scenarios 


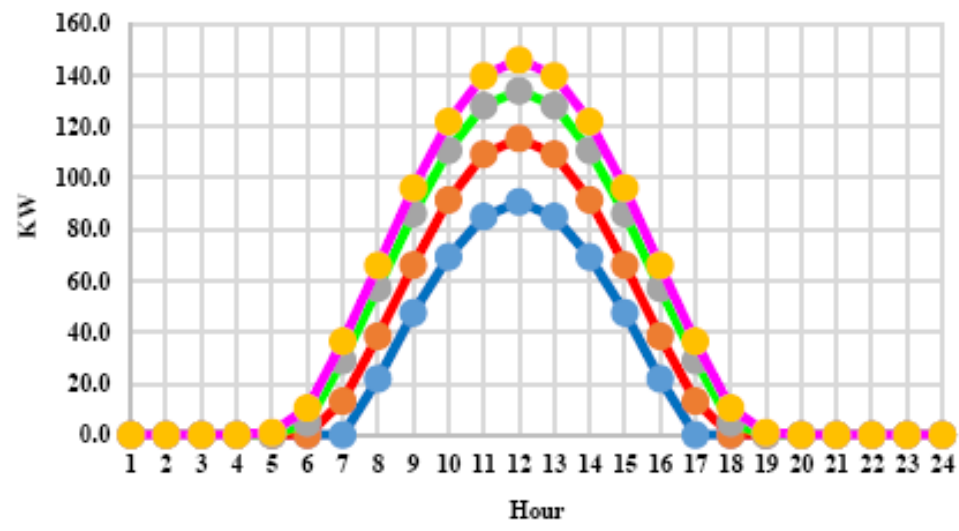

Figure4. Productive capability of solar unit for different scenarios

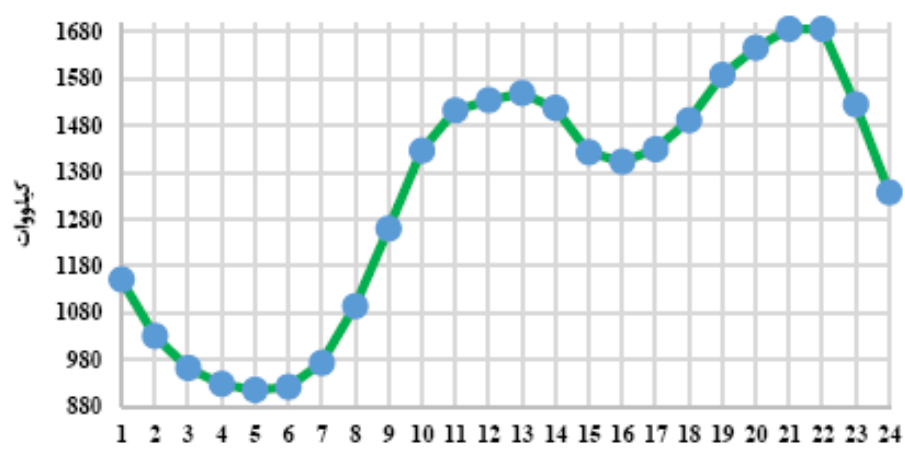

Figure5. Base load profile of grid

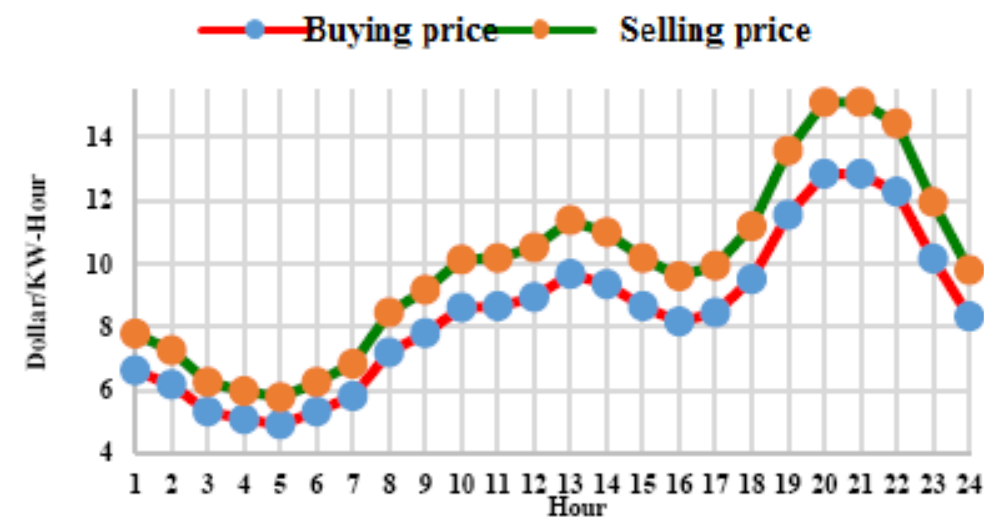

Figure6. Selling and buying prices of electricity during daily hours

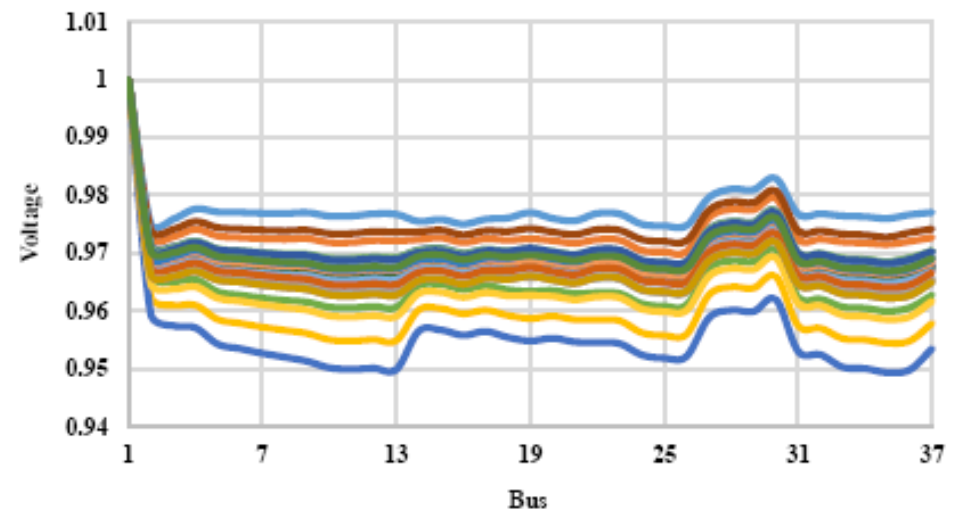

Figure7. Grid voltage profile in firs scenario and different hours 


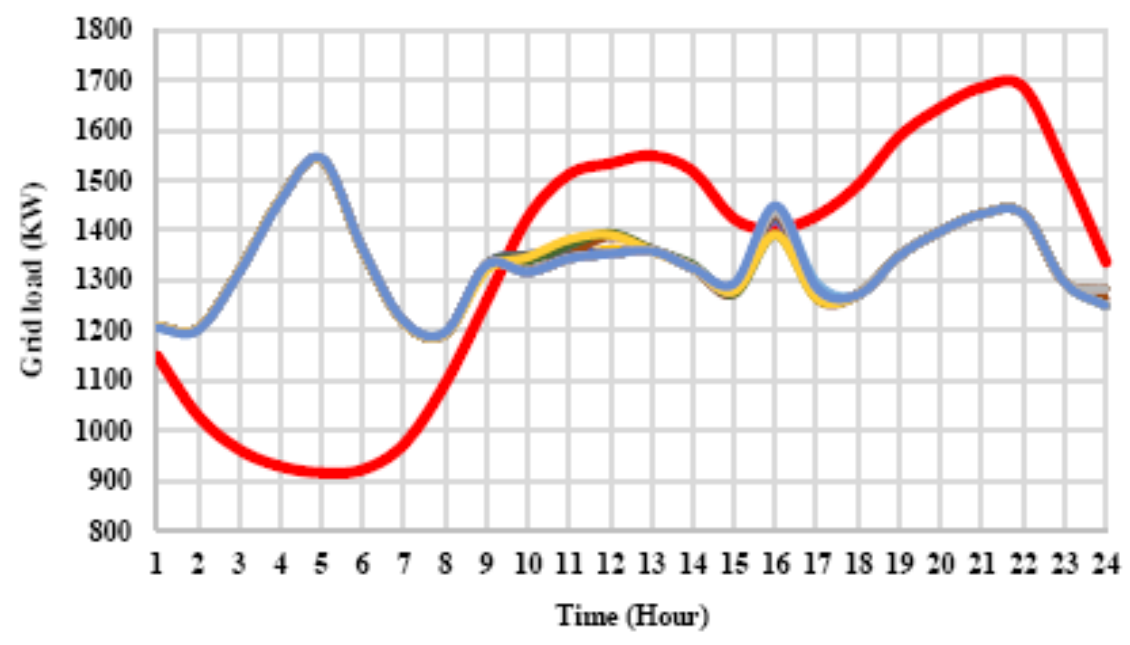

Figure8. Grid load profile for all scenarios

Figure 9 illustrates losses of active capability of gird in different hours. As it is shown, in this state also the most amounts of losses in active capability of grid are at initial hours of day so that grid load is increased at these hours.

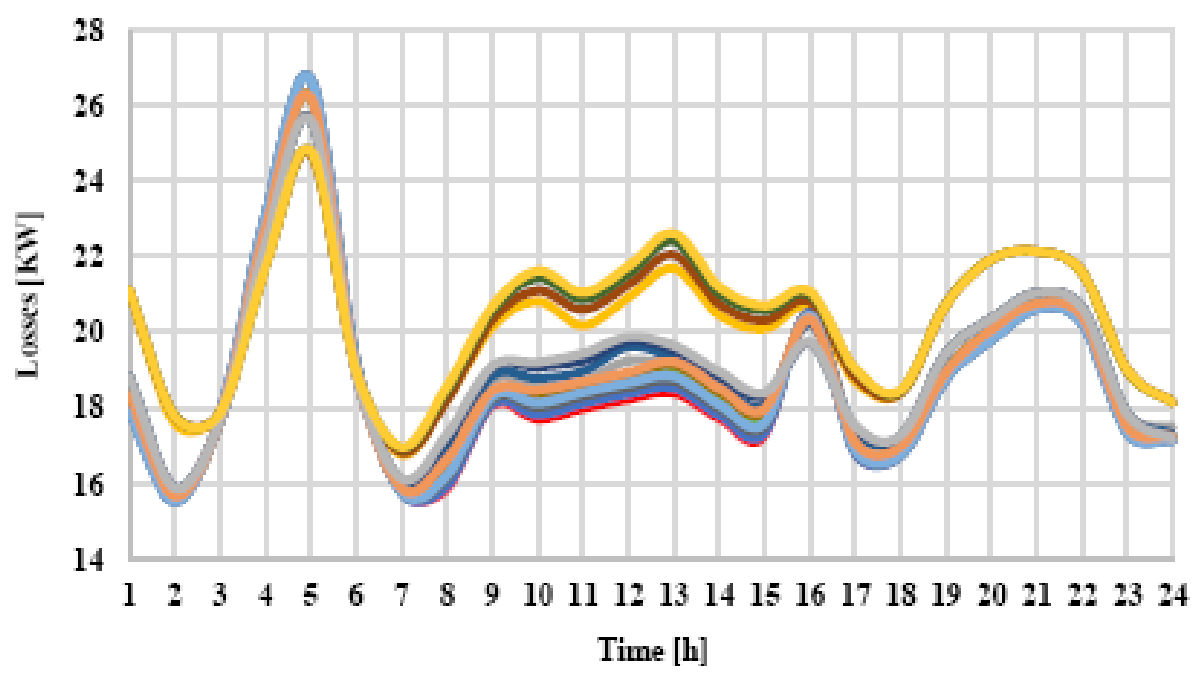

Figure9. Losses of active capability of grid for all scenarios

Figure 10 depicts three states for grid including 1) base load, 2) grid load regardless of electric vehicles and 3) grid load considering electric vehicles.

The plotted diagrams in figure indicate that grid load at initial hours of day has been increased considering electric vehicles. This increase in load is because of charging vehicles during these hours. The obtained results indicate that majority of vehicles have been charged in 3, 4, and 5 hours in morning. All vehicles have not been charged in at 19, 20, and 21 and some of these vehicles have been charged at these hours that it is depicted in diagram.

In case of discharging of vehicles, it has been done at 1, 19,20,21, and 22. This can be seen clearly in diagram. Where, green diagram is lower than purple diagram this indicates that grid load is deceased through vehicles discharging.

Red, purple and green lines in figure 10 respectively depicts grid based load, first scenario load and first scenario load considering vehicles powers.

As it is seen, vehicle SOC has been dropped since 8 o'clock. The vehicle has been moving at this time; therefore, some amount of charge of vehicle has been lost. 


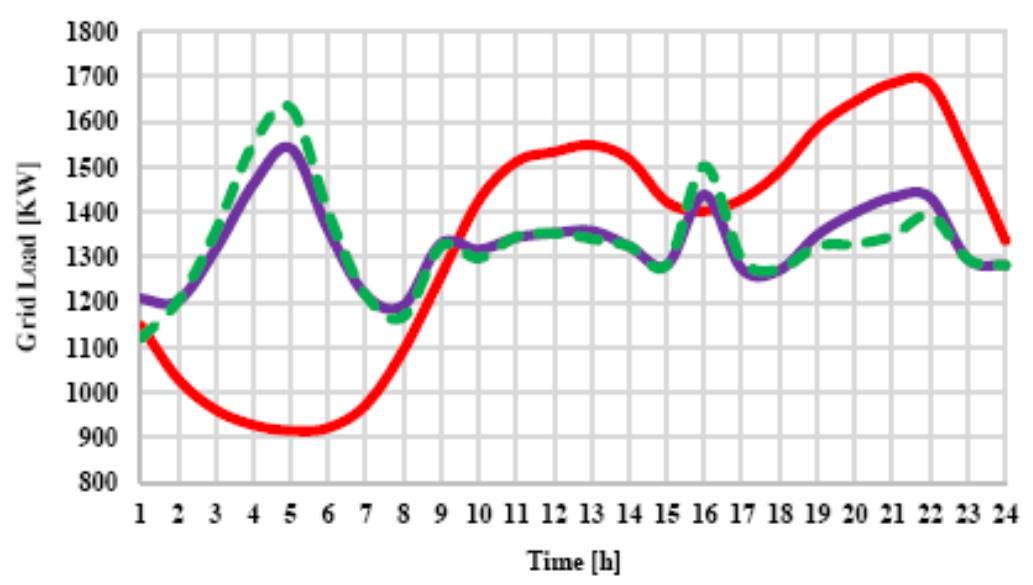

Figure10. Grid load profile in first scenario and considering electric vehicles

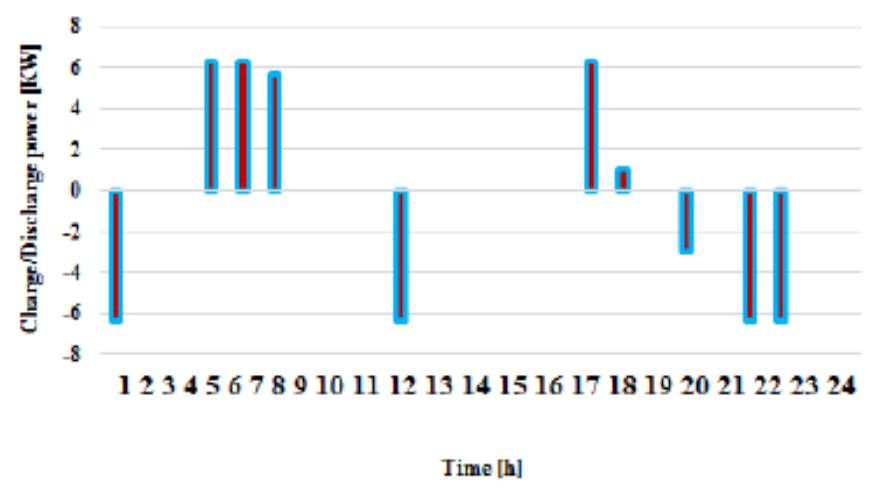

Figure(25-4). Charge of vehicle number 1 in first scenario

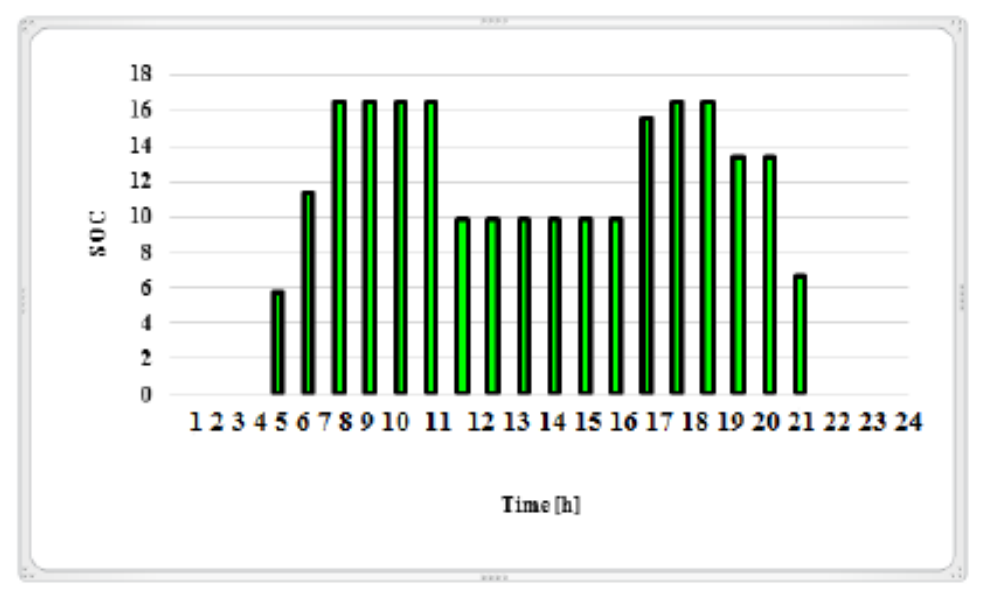

Figure(26-4). SOC changing trend for vehicle number 1 in first scenario

The vehicle is discharged a 21 and 22 so that it is running out of charge at 22 and since there is not any other charge, it is remained with SOC level of zero until the end of day.

\section{Conclusion}

An exploitation plan of agent-based smart grid was proposed in this paper. In this plan, distribution grid is divided into several agents that each of them is responsible to control and manage its equipment. Agents would determine the productive capability of each of units or amount of bought power from grid having information and prices. In this plan, agents have this capability to transfer a part of their load to other hours. Therefore, a part of load is transferred to low-load hours at the peak hours that electricity price is higher than other hours. This would lead to more profit for each agent. Because agents tend to have state of high profit. This state will be obtained solving an optimization problem. 


\section{REFERENCES}

[1] Farhangi H. The path of the smart grid. IEEE Pow Energy Mag 2010;8:18-28.

[2] Blumsack S, Fernández A. Ready or not, here comes the smart grid! Energy 2012;37:61-8.

[3] Gellings C. The smart grid: enabling energy efficiency and demand response. Fairmont Press; 2009.

[4] Huang D, Billinton R. Effects of load sector demand side management applications in generating capacity adequacy assessment. IEEE Trans Pow Syst 2012;27:335-43.

[5] Kostková K, Omelina L, Kycina P, Jamrich P. An introduction to load management. Electr Pow Syst Res 2013;95:184-91.

[6] Albadi M, El-Saadany E. Demand response in electricity markets: an overview. In: IEEE power engineering society general meeting, June 2007. p. 1-5.

[7] Rahimi F, Ipakchi A. Demand response as a market resource under the smart grid paradigm. IEEE Trans Smart Grid 2010;1:82-8.

[8] Palensky P, Dietrich D. Demand side management: demand response, intelligent energy systems, and smart loads. IEEE Trans Ind Inf 2011;7:381-8.

[9] EU Commission Staff Working Document: incorporing demand side flexibility, in particular demand response, in electricity markets; 2013. <http:// ec.europa.eu/>.

[10] Logenthiran T, Srinivasan D, Shun TZ. Demand side management in smart grid using heuristic optimization. IEEE Trans Smart Grid 2012;3:1244-52.

[11] Strbac G. Demand side management: benefits and challenges. Energy Policy 2008;36:4419-26.

[12] International Energy Agency - Annual Report, 2012. 〈http://www.ieadsm.org/ >.

[13] Siano P. Demand response and smart grids: a survey. Renew Sustain Energy Rev 2014;30:46178.

[14] Smart Grid Global Impact Report, 2013. <http://www.smartgridimpact.com/>.

[15] Smart Grids Proyects Portal, 2013. <https://portal.smartgridsprojects.eu/>.

[16] Morais H, Kàdàr P, Faria P, Vale ZA, Khodr H. Optimal scheduling of a renewable micro-grid in an isolated load area using mixed-integer linear programming. Renew Energy 2010; 35(1):151-6.

[17] Khodr H, Halabi NE, García-Gracia M. Intelligent renewable microgrid scheduling controlled by a virtual power producer: a laboratory experience. Renew Energy 2012; 48:269-75.

[18] Kriett PO, Salani M. Optimal control of a residential microgrid. Energy 2012; 42(1):321-30.

[19] Naraharisetti PK, Karimi I, Anand A, Lee DY. A linear diversity constrainte application to scheduling in microgrids. Energy 2011; 36(7):4235-43.

[20] Moghaddam AA, Seifi A, Niknam T, Pahlavani MRA. Multi-objective operation management of a renewable MG (micro-grid) with back-up micro-turbine/ fuel cell/battery hybrid power source. Energy 2011; 36(11):6490-507.

[21] Basu AK, Chowdhury S, Chowdhury S, Paul S. Microgrids: energy management by strategic deployment of DERsea comprehensive survey. Renew Sust Energ Rev 2011; 15(9):4348-56.

[22] Xiong G, Chen C, Kishore S, Yener A. Smart (in-home) power scheduling for demand response on the smart grid. In: Innovative smart grid technologies (ISGT), IEEE PES 2011. p. 1-7.

[23] Pedrasa MAA, Spooner TD, MacGill IF. A novel energy service model and optimal scheduling algorithm for residential distributed energy resources. Electr Power Syst Res 2011; 81(12):215563.

[24] Rastegar M, Fotuhi-Firuzabad M, Aminifar F. Load commitment in a smart home. Appl Energy 2012; 96:45-54.

[25] Elma O, Selamogullari US. A comparative sizing analysis of a renewable energy supplied standalone house considering both demand side and source side dynamics. Appl Energy 2012; 96:4008.

[26] Mehleri ED, Sarimveis H, Markatos NC, Papageorgiou LG. A mathematical programming approach for optimal design of distributed energy systems at the neighbourhood level. Energy 2012; 44(1):96-104. 
[27] Alagoz B, Kaygusuz A, Karabiber A. A user-mode distributed energy management architecture for smart grid applications. Energy 2012; 44(1):167-77.

[28] Siddiqui AS, Marnay C. Distributed generation investment by a microgrid under uncertainty. Energy 2008; 33(12):1729-37.

[29] Doagou-Mojarrad H, Gharehpetian G, Rastegar H, Olamaei J. Optimal placement and sizing of \{DG\} (distributed generation) units in distribution networks by novel hybrid evolutionary algorithm. Energy 2013; 54(0):129-38.

[30] Kuznetsova E, Li YF, Ruiz C, Zio E, Ault G, Bell K. Reinforcement learning for microgrid energy management. Energy 2013; 59:133-46.

[31] Mitra S, Sun L, Grossmann IE. Optimal scheduling of industrial combined heat and power plants under time-sensitive electricity prices. Energy 2013; 54(0): 194-211.

[32] Kusch W, Schmidla T, Stadler I. Consequences for district heating and natural gas grids when aiming towards 100\% electricity supply with renewables. Energy 2012; 48(1):153-9.

[33] Panto M. Stochastic optimal charging of electric-drive vehicles with renewable energy. Energy 2011; 36(11):6567-76.

[34] Fernandes C, Frías P, Latorre JM. Impact of vehicle-to-grid on power system operation costs: the Spanish case study. Appl Energy 2012; 96:194-202.

[35] Saber A, Venayagamoorthy G. Resource scheduling under uncertainty in a smart grid with renewables and plug-in vehicles. IEEE Syst J 2012; 6(1):103-9.

[36] Kristoffersen TK, Capion K, Meibom P. Optimal charging of electric drive vehicles in a market environment. Appl Energy 2011; 88(5):1940-8.

[37] Zhang Q, Mclellan BC, Tezuka T, Ishihara KN. A methodology for economic and environmental analysis of electric vehicles with different operational conditions. Energy 2013. http://dx.doi.org/10.1016/j.energy.2013.01.025.

[38] Borba BSM, Szklo A, Schaeffer R. Plug-in hybrid electric vehicles as a way to maximize the integration of variable renewable energy in power systems: the case of wind generation in northeastern brazil. Energy 2012; 37(1):469-81.

[39] Muratori M, Moran MJ, Serra E, Rizzoni G. Highly-resolved modeling of personal transportation energy consumption in the United States. Energy 2013; 58:168-77.

[40] Shafie-khah M, Moghaddam MP, Sheikh-El-Eslami MK, Rahmani-Andebili M. Modeling of interactions between market regulations and behavior of plug-in electric vehicle aggregators in a virtual power market environment. Energy 2012; 40(1):139-50.

[41] Juul N. Battery prices and capacity sensitivity: electric drive vehicles. Energy 2012; 47(1):40310.

[42] Kiviluoma J, Meibom P. Methodology for modelling plug-in electric vehicles in the power system and cost estimates for a system with either smart or dumb electric vehicles. Energy 2011; 36(3):1758-67.

[43] Hedegaard K, Ravn H, Juul N, Meibom P. Effects of electric vehicles on power systems in northern Europe. Energy 2012; 48(1):356-68.

[44] Li Z, Ouyang M. The pricing of charging for electric vehicles in China dilemma and solution. Energy 2011; 36(9):5765-78.

[45] Densing M, Turton H, BÃăuml G. Conditions for the successful deployment of electric vehicles a global energy systemperspective. Energy 2012; 47(1):137-49.

[46] Kromer MA, Bandivadekar A, Evans C. Long-term greenhouse gas emission and petroleum reduction goals: evolutionary pathways for the light-duty vehicle sector. Energy 2010; 35(1):387-97.

[47] Hao H, Wang H, Ouyang M. Fuel conservation and GHG (greenhouse gas) emissions mitigation scenarios for Chinas passenger vehicle fleet. Energy 2011; 36(11):6520-8.

[48] Smith WJ. Can EV (electric vehicles) address Irelands CO2 emissions from transport? Energy 2010; 35(12):4514-21.

[49] Sioshansi R, Denholm P. The value of plug-in hybrid electric vehicles as grid resources. Energy J 2010; 31(3):1-24. 
[50] Sioshansi R. Modeling the impacts of electricity tariffs on plug-in hybrid electric vehicle charging, costs, and emissions. Oper Res 2012; 43(4):1199-204.

[51] Sousa T, Morais H, Soares J, Vale Z. Day-ahead resource scheduling in smart grids considering vehicle-to-grid and network constraints. Appl Energy 2012; 96:183-93.

[52] K. T. C. Chunhua Liu, Diyun WU, Shuang Gao, "Opportunities and Challenges of Vehicle-toHome, Vehicle-to-Vehicle, and Vehicle-to-Grid Technologies", IEEE, vol. 101, pp. 2409-2427, 2013.

[53] M. M. Collins and G. H. Mader, "The Timing of EV Recharging and Its Effect on Utilities," IEEE Transactions on Vehicular Technology, vol. 32, no. 1, pp. 90-97, 1983.

[54] F. Koyanagi and Y. Uriu, "A Strategy of Load Leveling by Charging and Discharging Time Control of Electric Vehicles," IEEE Transactions on Power Systems, vol. 13, no. 3, pp. 11791184, 1998.

[55] IEEE 37-bus Distribution Feeder. <http://ewh.ieee.org/soc/pes/dsacom/ testfeeders>; [Last update August 2013]. 